\title{
Communication \\ Variable Populations of Grapevine Virus T Are Present in Vineyards of Hungary
}

\author{
Emese Demian ${ }^{1,+}{ }^{+}$, Aliz Holczbauer ${ }^{1,+}{ }^{+}$, Zsuzsanna Nagyne Galbacs ${ }^{1}$, Nikoletta Jaksa-Czotter ${ }^{1}$, Mihaly Turcsan ${ }^{2}$, \\ Robert Olah ${ }^{2}$ and Eva Varallyay $1, *$ (D)
}

1 Institute of Plant Protection, Hungarian University of Agriculture and Life Sciences, Ménesi Road 44, H-1118 Budapest, Hungary; emese.demian@gmail.com (E.D.); holczbaueraliz@gmail.com (A.H.); Nagyne.Galbacs.Zsuzsanna@uni-mate.hu (Z.N.G.); Jaksa-Czotter.Nikoletta@uni-mate.hu (N.J.-C.)

2 Institute for Viticulture and Oenology, Hungarian University of Agriculture and Life Sciences, Villányi Str. 29-43, H-1118 Budapest, Hungary; turcsan.mihaly@uni-mate.hu (M.T.); olah.robert@uni-mate.hu (R.O.)

* Correspondence: Varallyay.Eva@uni-mate.hu

+ These authors contributed equally to this work.

Citation: Demian, E.; Holczbauer, A.; Galbacs, Z.N.; Jaksa-Czotter, N.; Turcsan, M.; Olah, R.; Varallyay, E. Variable Populations of Grapevine Virus T Are Present in Vineyards of Hungary. Viruses 2021, 13, 1119 https://doi.org/10.3390/v13061119

Academic Editors: Leyi Wang and Ganwu Li

Received: 17 May 2021

Accepted: 9 June 2021

Published: 10 June 2021

Publisher's Note: MDPI stays neutral with regard to jurisdictional claims in published maps and institutional affiliations.

Copyright: (c) 2021 by the authors. Licensee MDPI, Basel, Switzerland. This article is an open access article distributed under the terms and conditions of the Creative Commons Attribution (CC BY) license (https:/ / creativecommons.org/licenses/by/ $4.0 /)$.

\begin{abstract}
Grapevine virus T (GVT) is a recently described foveavirus, which was identified from a transcriptome of a Teroldego grapevine cultivar in 2017. Recently, we surveyed vineyards and rootstock plantations in Hungary using small RNA (sRNA) high-throughput sequencing (HTS), at a time when GVT had not yet been described. A re-analysis of our sRNA HTS datasets and a survey of grapevines by RT-PCR revealed the presence of GVT in most of the vineyards tested, while at rootstock fields its presence was very rare. The presence and high variability of the virus in the country was confirmed by sequence analysis of strains originating from different vineyards. In this study, we demonstrate the presence of GVT in Hungary and show its high diversity, suggesting that GVT presence may not seriously affect grapevine health and that it could have been present in European vineyards for a long time as a latent infection.
\end{abstract}

Keywords: grapevine virus T; foveavirus; grapevine; high-throughput sequencing; diversity

\section{Introduction}

Grapevines serve as the basis of the wine industry, and the table grape is an agronomically important plant. Many chemicals are used to protect these vines from pathogens, but without an efficient plant protection method against viruses they will still be exposed to them. Grapevines are able to be infected by more than 80 viruses or viroids [1].

While traditional serological tests and RT-PCR can only detect the presence of the investigated virus, new high-throughput sequencing-based metagenomics methods can disclose the presence of all pathogens in a sample. High-throughput sequencing (HTS)based virus diagnostics of grapevines is widespread and could lead to the characterization of the viromes of vineyards [2] and vines showing various symptoms [3]. Moreover, the evolution in the bioinformatic pipeline makes it possible to assemble the genomes of previously unknown viruses and viroids using these data [4,5]. This evolution in sequence data analysis has led to the description of an increasing number of grapevineinfecting viruses.

Grapevine virus T (GVT) is one of the viruses discovered by HTS in recent years. The original description of this new foveavirus dates back to 2017, when re-analysis of published grapevine transcriptome data revealed its presence in an Italian Teroldego cultivar [6]. The available sequence of the putative virus induced new analyses and revealed its widespread presence in Slovakia and the Czech Republic [7], Croatia [8], France [9], and Germany [10]. These descriptions were mainly based on the re-investigation of previously deposited RNA sequencing datasets and validation by independent methods. These efforts led to 
the identification of 26 almost full length genomic GVT sequences. However, in most of these cases, the $5^{\prime}$ and $3^{\prime}$ UTR of the sequences are missing or are incomplete. Recently, the reference genome of GVT (NC_035203) and the originally announced GVT full-length genome (MF095096) were removed from the GenBank because they solely relied on HTS data. The only report of GVT found when the causative agent of a grapevine disease was investigated was published in China. However, in this report, the symptomatic plant was infected with other viruses, the presence of which could be connected to the symptoms, including: grapevine leafroll-associated virus 1, grapevine red globe virus, and grapevine Pinot gris virus [11]. GVT was also reported overseas in California, where it was identified in an introduced Italian Lambrusca and, later, from a Russian, Georgian, and Croatian cultivar with Italian origin, which showed no symptoms [12].

Recently, we surveyed Hungarian vineyards and rootstock fields for the presence of viruses using small RNA (sRNA) HTS $[13,14]$. When we undertook our bioinformatics analysis, the genome of GVT was not available. However, its widespread, latent presence in all investigated European samples prompted us to reinvestigate our sRNA HTS datasets for its presence.

\section{Materials and Methods}

\subsection{Source of Data and Samples}

Our deposited datasets in the NCBI GenBank GEO, GSE106240 and GSE130994, contain sRNA sequence data from 18 samples representing 15 vineyards, and samples representing 17 certified rootstock fields and two rootstock collections, respectively (Table S1). We used these datasets for the bioinformatics analysis. For RT-PCR analysis, we used the originally extracted RNAs and RNA pools of these surveys.

\subsection{Bioinformatics Analysis}

From the sequenced sRNA reads we built up longer contigs using a de novo assembler of CLC Genomic Workbench (CLCbio, Aarhus, Denmark) software (with default options: word size 20, bubble size 50, and simple contig sequences and min $35 \mathrm{nt}$ length), and searched for GVT-specific contigs. For BLASTn analysis, we used the sequence of the retracted reference genome (Supplementary Material S1).

Small RNA reads (both without and with redundancy) were directly mapped to the GVT reference genome. In the latter case, we calculated a normalized RPMR (number of redundant virus specific reads/million sequenced reads). Consensus sequences of the sRNA reads were prepared (extract consensus function of CLC) and, with the classical sequence analysis function of CLC, the coverage of the genome by virus-specific sRNAs was calculated as a percentage (Tables S2 and S3).

\subsection{RT-PCR Validation}

The cDNAs were synthetized using random primer and the RevertAid First Strand cDNA kit (Thermo Fisher Scientific, Waltham, MA, USA) from the RNA of individuals or the pooled RNAs representing the vineyards (the same RNA which was used to prepare the sRNA sequencing libraries). The PCR amplification was done by Q5 DNA polymerase (New England Biolabs), using two different sets of primers (Table S4). Primers designed by Glasa et al. [7] to amplify the $903 \mathrm{nt}$ long parts of the viral genome were redesigned according to the sRNA sequences present in our samples, making them able to amplify a slightly longer (904 bp) product. A parallel PCR, using degenerated primers from Diaz-Lara et al. [12], which were optimized to amplify diverse variants of the virus, was also conducted.

\subsection{Phylogenetic Analysis}

To investigate the phylogenetic correlations of the GVT variants present in the country, we cloned the amplified 904 bp long product to a pJET vector (Thermo Fisher Scientific, following the manufacturer's recommendations). One clone from each positive vineyard 
was Sanger sequenced and their sequences were deposited into GenBank (see Table 1 for their accession numbers, and their nucleotide and amino acid identity according to the GVT reference genome). Rootstocks had different geographical origins, which is why we did not include the corresponding isolates in the phylogenetic analysis. Phylogenetic analysis was conducted using MEGA7 and the neighbor-joining method.

Table 1. GVT sequences, which were deposited into NCBI GenBank, together with their accession number. Nucleotide sequences of the partial sequences were pairwise compared by BLASTn algorithm to both the GVT reference genome (Supplementary Material S1) and the GFVA sequence (MN553040). This pairwise comparison was done by BLASTp for the $\mathrm{CP}$ coding part of the partial sequences, and for calculating the identity and positivity in the amino acid percentage.

\begin{tabular}{ccccccc}
\hline Library & Isolate & $\begin{array}{c}\text { GenBank } \\
\text { Identifier }\end{array}$ & $\begin{array}{c}\text { Identity to } \\
\text { GVT at } \\
\text { Nucleotide } \\
\text { Level \% }\end{array}$ & $\begin{array}{c}\text { Identity to the } \\
\text { GFVA at } \\
\text { Nucleotide Level } \\
\%\end{array}$ & $\begin{array}{c}\text { Identity/Positivity } \\
\text { to the CP of the } \\
\text { GVT at Amino } \\
\text { Acid Level \% }\end{array}$ & $\begin{array}{c}\text { Identity/Positivity } \\
\text { to the GFVA at } \\
\text { Amino Acid Level } \\
\text { \% }\end{array}$ \\
\hline TK & HUTK & MT211969 & 86 & 78 & $94 / 96$ & $85 / 93$ \\
PH & HUPH & MT211970 & 89 & 77 & $96 / 98$ & $86 / 93$ \\
PP & HUPP & MT211971 & 88 & 78 & $96 / 98$ & $81 / 89$ \\
CS & HUCS & MW377753 & 88 & 78 & $96 / 98$ & $82 / 89$ \\
ET & HUET & MT211974 & 87 & 78 & $95 / 98$ & $85 / 92$ \\
SZHT & HUSZHT & MT211975 & 87 & 78 & $95 / 98$ & $83 / 91$ \\
EH & HUEH & MT211976 & 82 & 77 & $93 / 96$ & $82 / 91$ \\
DF & HUDF & MT211977 & 82 & 76 & $96 / 95$ & $82 / 91$ \\
BV & HUBV & MT211978 & 89 & 78 & $96 / 97$ & $85 / 93$ \\
MK1 & HUMK1 & MW377754 & 84 & 88 & $96 / 99$ & $85 / 91$ \\
MK7 & HUMK7 & MT211981 & & & $81 / 90$ \\
\hline
\end{tabular}

\section{Results and Discussion}

To determine whether GVT is present in Hungary, we re-analyzed our sRNA HTS data generated in surveys of vineyards and rootstock plantations [13,14]. To our surprise, we found GVT-specific contigs in only three samples from the vineyards: 9_SZHT (Furmint vineyard), 13_BV (five ancient varieties in a collection), and 18_MK7 (Teleki Kober 5C rootstock cultivar sampled in the vineyards) (Table S2), and in none of the rootstock libraries (Table S3). The GVT genome shows high variability, so it is possible to lose hits when a strain showing low homology to the reference genome is present in the sample. To overcome this problem, we prepared a consensus GVT sequence using 26 full-length GVT sequences available in the GenBank (the same ones which were used for primer sequence optimization [12]) and blasted the contigs of the libraries against it. Two additional hits, 12_DF and 14_AD, one from a Furmint vineyard and the other from a rootstock plantation, were found. Direct BLAST of these contigs showed that the one presented in 14_AD showed $100 \%$ similarity to a Vitis vinifera sequence, which is a false positive. It is possible that during the GVT genome assembly, a read of the host was mistakenly incorporated into the virus genome. During our previous work, we noted that the presence of the contigs did not always coincide with the presence of a virus, which is why, using both the GVT reference genome and its consensus sequence, we directly mapped the sRNA reads of the libraries (map to the reference function of CLC), both with and without redundancy.

During our previous surveys, we found that the presence of the virus could be validated later if, besides the presence of a virus-specific contig, the RPMR was higher than 200 and the coverage of the genome was higher than 60\% [13,14]. In the case of GVT, the number of virus-specific reads was very low and never coincided with an acceptable coverage. These results indicated that, in contrast to the reports from Slovakia and the Czech Republic [7], GVT is not abundant in Hungary.

During our previous surveys, we found that detection of another foveavirus, grapevine rupestris stem pitting-associated virus (GRSPaV), the closest relative of GVT, failed using sRNA HTS in most cases. The number of GRSPaV-specific sRNAs was very low in the infected plants $[13,14]$, while virus-specific RT-PCR could detect its presence. To test if GVT 
was present in additional samples, in spite of the low level of GVT-specific sRNAs, RT-PCR with GVT-specific primers was conducted, amplifying part of its coat protein.

The results of the amplification using the RNA pools of the vineyards revealed the presence of GVT in more samples than the sRNA HTS did (Figure 1) (Figure S1).

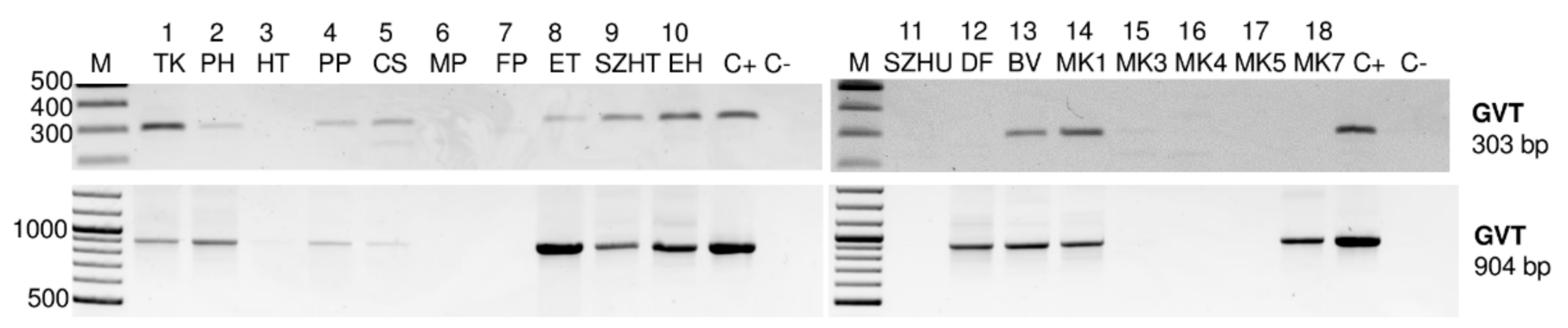

Figure 1. Validation of sRNA HTS by RT-PCR of the vineyard pools for the presence of GVT. Amplification was done using two different sets of primers, amplifying the 303 or 904 bp region of the coat protein coding region. Sample numbers, together with the vineyard codes, were used. M-GeneRuler 100 bp Plus, C-/C+ negative, and positive controls using water or cDNA prepared from a virus infected plant.

In addition to 9_SZHT, 13_BV, and 18_MK7, we detected a virus-specific product in 1_TK, 2_PH, 4_PP, 5_CS, 8_ET, 10_EH, 12_DF, 14_MK1, and 15_TC. Results with different primers correlated quite well, but in 12_DF and 18_MK7 we obtained the product only when amplifying a longer product (Figure 1).

To reveal how widespread the infection is at different vineyards, sampled vines were individually tested for the presence of GVT (Figures S2 and S3, Tables S4-S6). This test showed a widespread presence of the virus at the vineyards, revealing that more than $93 \%$ of the tested plants (59/63) were GVT infected (Figure S2 and Table S5). In the rootstock fields, only two infections were found and GVT presence was also rare at the rootstock variety collections: 1/34 and 10/33 at 11_P and 15_TC, respectively (Figure S3 and Tables S5 and S6).

The low coverage of the GVT genome did not allow us to use the sRNA datasets to see how different the isolates were, and is why cloned, amplified RT-PCR products from each field were sequenced. The variants present in Hungary showed high variability, $82-89 \%$ nucleotide and $92-96 \%$ amino acid identity with the Italian Teldorego isolate, suggesting their different origins (Table 1). Previous analyses of GVT full-length genomes and $\mathrm{CP}$ coding regions have demonstrated the existence of seven clusters of isolates [9]. Phylogenetic analysis of the Hungarian variants showed that they cluster in Group I or the most distantly related Group IV, while the HUMK1 variant did not group with any of the previously identified groups (Figure 2).

$\mathrm{DF}, \mathrm{EH}$, and MK1 are vineyards in Tokaj, in the northeast part of the country, planted with Furmint, an ancient Hungarian cultivar [13]. The DF and EH plantations are more than 100 years old, while we have no information about MK1's age. In Group IV, MH388491 represents a Hungarian breed: Poloskei muskotaly (bred in 1967), suggesting this clade could represent GVTs that have been in the country for a long time. Other Group I GVT variants were collected from different widely grown cultivars (including one additional Furmint, SZHT), which could originate from the international market and were planted much later. Vineyards where GVT was not present in the sampled plants were planted recently (within the last 10 years). 


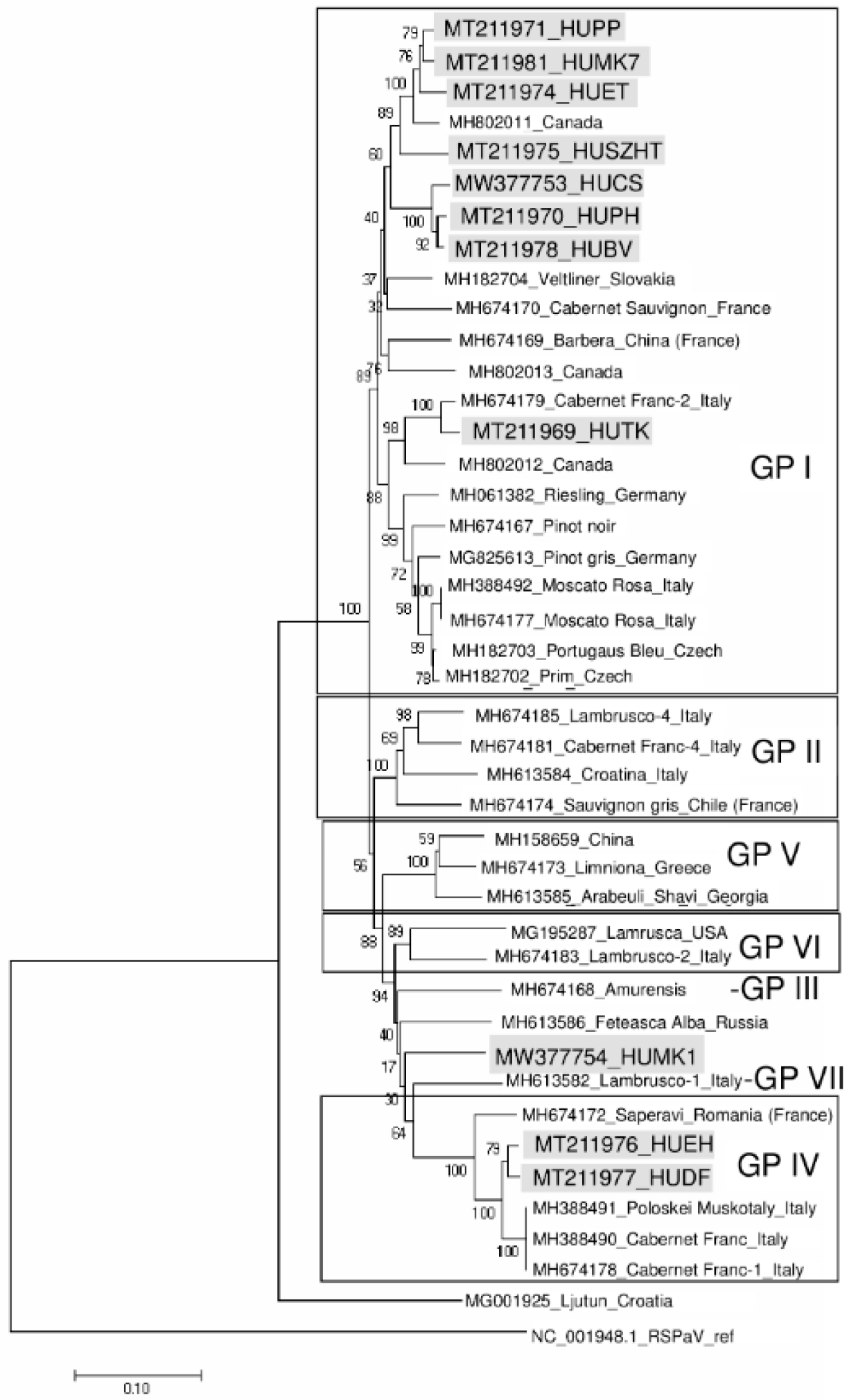

Figure 2. Phylogenetic relationship of GVT isolates. The evolutionary history was inferred based on the nucleotide sequence of a $904 \mathrm{bp}$ RT-PCR product (coding for the coat protein) using the neighbor-joining method. The percentage of replicate trees, in which the associated taxa clustered together in the bootstrap test (500 replicates), are shown next to the branches. The tree is drawn to scale, with branch lengths in the same units as those of the evolutionary distances used to infer the phylogenetic tree. The analysis involved 43 nucleotide sequences. Their GenBank accession numbers are indicated. Hungarian isolates are marked with grey boxes. GRSPaV reference genome was used as an outgroup. 


\section{Discussion}

Re-analysis of RNA samples from our previous surveys revealed high prevalence of GVT in the country. Based on studies on GRSPaV, foveaviruses have no identified vectors [15] and could be maintained during vegetative propagation. If this is true, GVT was present in Europe for a long time and could have been disseminated by vegetative propagation of the host. Elimination of foveaviruses from grapevines, as was shown for GRSPaV, is very challenging, and the methods used to do so show different efficiencies [16,17]. Meristem culture-based elimination could not $100 \%$ eliminate GRSPaV or GVT, which could explain their almost even distribution in the infected cultivars. However, chemotherapy and somatic embryogenesis-based methods gave better results for GRSPaV and for both viruses, which could be optimized in the future if new regulations target foveaviruses $[16,18]$.

GVT was only described recently, and it can be present in grapevines without any visible symptoms. Its European origin is highly probable, as it has been identified only in European cultivars. The vineyards of Europe were almost totally replanted after phyloxera epidemics. However, Vitis sylvestris species in the wild flora could survive. Their virome can reveal information about the presence of endemic viruses. Investigation of the virome of a Vitis sylvestris population in Switzerland revealed the presence of a foveavirus, grapevine foveavirus A (GFVA-MN553040) [19]. GFVA is a highly divergent GVT isolate, or could even be a distinct foveavirus. Comparison of the CP coding region of Hungarian GVT isolates to the CP of GFVA showed higher than $80 \%$ amino acid identity and higher than $90 \%$ positivity, supporting the close relationship of GVT and GFVA (Table 1). This finding suggests that the origin of GVT may be from the endemic natural flora, with a common ancestor with GFVA, but this question needs further investigation in the future.

\section{Conclusions}

High-throughput sequencing techniques offer the possibility of gaining sequence information about previously unknown viruses. A recent paper, investigating the biological information in publications describing new viruses of fruit trees, revealed a big gap in their biological data, including host range studies and symptom descriptions, which could affect their correct risk assessment [20]. This is the knowledge that is still missing and should be detailed for GVT in the future. Currently, we can only show that GVT is widespread in vineyards, but it is not possible to directly correlate any deteriorating symptoms to its presence.

Latency and the symptomless nature of GVT infection, together with high variability of the genome, result in uncertainty in the viral diagnosis. The question of regulating GVT is open, but more information is needed about how GVT affects its grapevine host to make a sensible decision.

Supplementary Materials: The following are available online at https://www.mdpi.com/article/ 10.3390/v13061119/s1: Tables S1 and S7 spreadsheets, Supplementary Figures S1-S3, and Supplementary Material S1, containing the retracted sequence of the originally described GVT genome (MF095096), which was temporarily the reference genome of GVT (NC_035203).

Author Contributions: E.D.: investigation, formal analysis, data curation, and visualization; A.H.: investigation, formal analysis, and visualization; Z.N.G.: investigation, data curation, and visualization; N.J.-C.: investigation, data curation, formal analysis, and visualization; M.T.: investigation; R.O.: supervision, and funding acquisition; E.V.: conceptualization, methodology, funding acquisition, writing - original draft preparation, and writing-reviewing and editing. All authors have read and agreed to the published version of the manuscript.

Funding: This research was financially funded by the National Research, Development and Innovation Office (NKFIH), grant numbers: K119783, K131679.

Data Availability Statement: The sRNA HTS datasets analyzed can be found at NCBI GEO: GSE106240 and GSE130994. 
Acknowledgments: Mihaly Turcsan and Emese Demian are students at Hungarian University of Life Sciences, at the Doctoral School of Horticultural Sciences and Doctoral School of Biological Sciences, respectively. Aliz Holczbauer is a student at Eotvos Lorand University of Sciences. The authors would like to acknowledge the contribution of the COST Action FA 1407-DIVAS (Deep Investigation of Virus-Associated Sequences).

Conflicts of Interest: The authors declare no conflict of interest.

\section{References}

1. Martelli, G. Directory of virus and virus-like diseases of the grapevine and their agents. J. Plant Pathol. 2014, 96, 1-136. [CrossRef]

2. Coetzee, B.; Freeborough, M.-J.; Maree, H.J.; Celton, J.-M.; Rees, D.J.G.; Burger, J.T. Deep sequencing analysis of viruses infecting grapevines: Virome of a vineyard. Virology 2010, 400, 157-163. [CrossRef] [PubMed]

3. Hily, J.-M.; Candresse, T.; Garcia, S.; Vigne, E.; Tannière, M.; Komar, V.; Barnabé, G.; Alliaume, A.; Gilg, S.; Hommay, G.; et al. High-throughput sequencing and the viromic study of grapevine leaves: From the detection of grapevine-infecting viruses to the description of a new environmental tymovirales member. Front. Microbiol. 2018, 9. [CrossRef] [PubMed]

4. Giampetruzzi, A.; Roumi, V.; Roberto, R.; Malossini, U.; Yoshikawa, N.; La Notte, P.; Terlizzi, F.; Credi, R.; Saldarelli, P. A new grapevine virus discovered by deep sequencing of virus- and viroid-derived small rnas in cv pinot gris. Virus Res. 2012, 163, 262-268. [CrossRef] [PubMed]

5. Wu, Q.; Ding, S.W.; Zhang, Y.; Zhu, S. Identification of viruses and viroids by next-generation sequencing and homologydependent and homology-independent algorithms. Annu. Rev. Phytopathol. 2015, 53, 425-444. [CrossRef] [PubMed]

6. Jo, Y.; Song, M.-K.; Choi, H.; Park, J.-S.; Lee, J.-W.; Lian, S.; Lee, B.C.; Cho, W.K. Genome sequence of grapevine virus t, a novel foveavirus infecting grapevine. Genome Announc. 2017, 5, e00995-17. [CrossRef] [PubMed]

7. Glasa, M.; Predajňa, L.; Sihelská, N.; Šoltys, K.; Ruiz-García, A.B.; Olmos, A.; Wetzel, T.; Sabanadzovic, S. Grapevine virus t is relatively widespread in slovakia and czech republic and genetically diverse. Virus Genes 2018, 54, 737-741. [CrossRef] [PubMed]

8. Vončina, D.; Almeida, R.P.P. Screening of some croatian autochthonous grapevine varieties reveals a multitude of viruses, including novel ones. Arch. Virol. 2018, 163, 2239-2243. [CrossRef] [PubMed]

9. Nourinejhad Zarghani, S.; Hily, J.M.; Glasa, M.; Marais, A.; Wetzel, T.; Faure, C.; Vigne, E.; Velt, A.; Lemaire, O.; Boursiquot, J.M.; et al. Grapevine virus $\mathrm{t}$ diversity as revealed by full-length genome sequences assembled from high-throughput sequence data. PLoS ONE 2018, 13, e02060. [CrossRef] [PubMed]

10. Ruiz-García, A.B.; Okic, A.; Nourinejhad Zarghani, S.; Olmos, A.; Wetzel, T. First report of grapevine virus $\mathrm{t}$ in grapevine in germany. Plant Dis. 2018, 102, 1675. [CrossRef]

11. Yan, C.; Yin, H.; Li, Y.; Zhang, Y. First report of grapevine virus t infecting grapevine in china. Plant Dis. 2019, 104, 1262. [CrossRef]

12. Diaz-Lara, A.; Golino, D.; Preece, J.E.; Al Rwahnih, M. Development of rt-pcr degenerate primers to overcome the high genetic diversity of grapevine virus t. J. Virol. Methods 2020, 282, 113883. [CrossRef] [PubMed]

13. Czotter, N.; Molnar, J.; Szabó, E.; Demian, E.; Kontra, L.; Baksa, I.; Szittya, G.; Kocsis, L.; Deak, T.; Bisztray, G. Ngs of virus-derived small rnas as a diagnostic method used to determine viromes of hungarian vineyards. Front. Microbiol. 2018, 9, 122. [CrossRef]

14. Demian, E.; Jaksa-Czotter, N.; Molnar, J.; Tusnady, G.E.; Kocsis, L.; Varallyay, E. Grapevine rootstocks can be a source of infection with non-regulated viruses. Eur. J. Plant Pathol. 2020, 156, 897-912. [CrossRef]

15. Martelli, G.P.; Jelkmann, W. Foveavirus, a new plant virus genus. Arch. Virol. 1998, 143, 1245-1249. [CrossRef] [PubMed]

16. Skiada, F.G.; Maliogka, V.I.; Katis, N.I.; Eleftheriou, E.P. Elimination of grapevine rupestris stem pitting-associated virus (grspav) from two vitis vinifera cultivars by in vitro chemotherapy. Eur. J. Plant Pathol. 2013, 135, 407-414. [CrossRef]

17. Gribaudo, I.; Gambino, G.; Cuozzo, D.; Mannini, F. Attempts to eliminate grapevine rupestris stem pitting-associated virus from grapevine clones. J. Plant Pathol. 2006, 293-298. [CrossRef]

18. Turcsan, M.; Demian, E.; Varga, T.; Jaksa-Czotter, N.; Szegedi, E.; Olah, R.; Varallyay, E. Hts-based monitoring of the efficiency of somatic embryogenesis and meristem cultures used for virus elimination in grapevine. Plants 2020, 9, 1782. [CrossRef] [PubMed]

19. Reynard, J.-S.; Brodard, J.; Remoliff, E.; Lefebvre, M.; Schumpp, O.; Candresse, T. A novel foveavirus identified in wild grapevine (vitis vinifera subsp. Sylvestris). Arch. Virol. 2020, 165, 2999-3002. [CrossRef] [PubMed]

20. Hou, W.; Li, S.; Massart, S. Is there a "biological desert" with the discovery of new plant viruses? A retrospective analysis for new fruit tree viruses. Front. Microbiol. 2020, 11. [CrossRef] [PubMed] 